\title{
THE TYPES OF ORGANIZATIONAL CULTURE OF MIDDLE-SIZED RESTAURANTS IN THE NETHERLANDS SUITABLE FOR PLACING INDONESIAN STUDENT TRAINEES
}

\author{
Deborah Christine Widjaja \\ Lecturer in Hotel Management Programme, Petra Christian University, Surabaya \\ email: dwidjaja@peter.petra.ac.id \\ Klaes Eringa \\ Programme Director of the CHN University, School of Graduate Studies, \\ MA in International Service Management Programme, the Netherlands \\ email: k.eringa@chn.nl \\ Sjoerd Gehrels \\ Programme Director of the CHN University, School of Graduate Studies, \\ MA in International Hospitality Management Programme, the Netherlands \\ email: s.gehrels@chn.nl.
}

\begin{abstract}
Organizational culture plays a great influence in determining the success of one's performance in an organization. If someone fits with an organization's culture, it will be easier for him to adapt and perform at his best; but if not then he will experience lots of difficulties which will affect his performance. This study is intended to analyze the types of organizational culture of middle-sized restaurants in the Netherlands which is suitable for placing Indonesian student trainees to minimize problems appearing during their internship placement.
\end{abstract}

Keywords: organizational culture, service quality, perception, expectation, success factors.

In the field of service research, there is a strong shared belief that service employee satisfaction and customer satisfaction are interrelated and feed off each other. Even it is presumed that unless service employees are happy with their jobs, customer satisfaction will be difficult to achieve. (Heskett et al., 1997; Zeithaml and Bitner, 2000). The service profit chain introduced by James L. Heskett suggests that there are critical linkages among internal service quality; employee satisfaction and productivity; the value of services provided to customer; and ultimately customer satisfaction, retention and profits shown in figure 1.



Source: Heskett, 1997

\section{Figure 1. Service Profit Chain}

It signifies that making employees happy and satisfied is very important in order to make customers satisfied. There are several factors influencing employee satisfaction and productivity. We believe that one of the factors that influences employee satisfaction is organizational culture. Harris and Moran pointed out that the organization's culture of an organization influences the organization member's morale and productivity (1996). Organizational culture indeed has a powerful impact on employee's morale, satisfaction and service performance. This will lead to higher productivity which will lead to higher profitability. Those who agree with the culture will accept and conform but those who disagree will become frustrated and low productivity.

One definition of organizational culture is "values and beliefs that are shared by the people in a group and that tend to persist over time even when group membership changes." It is "the behaviour patterns or style of an organization that new employees are encouraged to follow by their fellow employees" (Sparrow, and Hiltrop, 1994; Frost et al., 1985). Further organizational culture is seen as "prevailing ideology" that people in an organization carry in their heads. It conveys "a sense of identity" of employees, provides unwritten and often unspoken guidelines for how to get along in the organization, and enhances the 
stability of the social system that they experience (Cameron and Quinn, 1999; Schein, 1992). Consequently anyone who wants to enter an organization must be ready to accept the culture shared by everybody in the organization unless he will be alienated by the group.

Cameron and Quinn categorize organizational culture into four different kinds, namely:

1. The Clan Culture: It is a friendly place to work where people share a lot of themselves. It is like an extended family. The leaders, or the heads of the organization, are considered to be mentors and perhaps even parent figures. The organization is held together by loyalty or tradition. Commitment is high. The organization emphasizes the longterm benefit of human resources development and attaches great importance to cohesion and morale. Success is defined in terms of sensitivity to customers and concern for people. The organization places a premium on teamwork, participation, empowerment and consensus.

2. The Adhocracy Culture: It is a dynamic, entrepreneurial, and creative place to work. People stick their necks out and take risks. The leaders are considered innovators and risk takers. The glue that holds the organization together is commitment to experimentation and innovation. The emphasis is on being on the leading edge. The organization's long-term emphasis is on growth and acquiring new resources. Success means gaining unique and new products or services. Being a product or service leader is important. The organization encourages individual initiative and freedom.

3. The Market Culture: It is a results-oriented organization whose major concern is with getting the job done. People are competitive and goal oriented. The leaders are hard-drivers, producers and competitors. They are tough and demanding. The glue that holds the organization together is an emphasis on winning. Reputation and success are common concerns. The long-term focus is on competitive actions and achievement of measurable goals and targets. Success is defined in terms of market share and penetration. Competitive pricing and market leadership are important. The organizational style is hard-driving competitiveness.

4. The Hierarchy Culture: It is a very formalized and structured place to work. Procedures govern what people do. The leaders pride themselves on being good coordinators and organizers who are efficiency-minded. Maintaining a smooth-running organization is most critical. Formal rules and policies hold the organization together. The longterm concern is on stability and performance with efficient, smooth operations. Success is defined in terms of dependable delivery, smooth scheduling, and low cost. The management of employees is concerned with secure employment and predicttability.

We believe that it will be easier for an employee to adapt and perform at his best if he agrees with the type of organizational culture that an organization possesses. On the other hand, if he does not fit with the organizational culture, it will as well affect his performance tremendously. In the end, the performance of the whole team will also be affected totally. We also believe that there are certain types of organizational culture preferred by a certain group of people based on the nationality or the society where he comes from because "societal culture" plays a major role in shaping an organizational culture (Schneider, 1990). However, it does not mean that people coming from a certain society background will consequently not fit with an organizational culture of an organization operating in another country with a certain societal culture background.

\section{Case Study}

Selected Indonesian Restaurants (SIR) and Fine Eastern Restaurants (FER) are middle-sized restaurants which operate in the Netherlands. In cooperation with Christelijke Hogeschool Noord Nederland (CHNN), Trisakti Academy and Petra Christian University (PCU), SIR and FER have been employing student trainees from Indonesia in the daily operation of the restaurant business. SIR has been in the project for about 13 years while FER has only been in the project for about 3 years. Moreover, Trisakti Academy which is based in Jakarta (the capital of Indonesia) has been in the project for about 13 years and PCU which is based in Surabaya has only been in the project for about 2 years. Based on the preliminary survey done among the student trainees of 2001, there were some critical points that required further study. From 16 student trainees of PCU placed in SIR or FER, 7 of them suggested that the biggest problem they had to face in their first months of their traineeship was with the restaurant owners or managers and the supervisors. 6 students answered that they encountered more serious problems with the other employees in the restaurants; and only 3 students suggested that they did not have any problems at all. Likewise, from 29 Trisakti student trainees, 17 suggested that dealing with the restaurant owners or managers and supervisors was the biggest problem that they had to face, while 7 of them encountered more problems with guests due to language barrier. 
The other 5 students had more problems with the other employees. None of the students answered that they had no problems at all. In other words, 53\% of the student trainees experienced more problems with the management of the restaurant; $24 \%$ had more problems with the other employees; $15 \%$ with the guests and only $6 \%$ answered that they had no problems and were happy with their relationship with everybody in the restaurants.

Moreover, the survey also indicated that 6 out of 16 Petra student trainees needed at least 2 months adaptation period; 4 others needed more than 2 months; 3 students needed 1 month and only 3 students needed 1 to 3 week period of adaptation. Regarding Trisakti students, 10 out of 29 student trainees needed 2 months adaptation period; 7 students needed 1 month; 4 students needed more than 2 months; 4 students needed 1 to 3 weeks and 4 students needed less than 1 week for their adaptation. In other words, $36 \%$ of the student trainees needed 2 months adaptation period, $22 \%$ needed 1 month, $18 \%$ needed more than 2 months, $16 \%$ needed 1 to 3 weeks and only $9 \%$ needed less than 1 week for their adaptation. It means that $55 \%$ of the student trainees needed at least 1 to 2 months of adaptation period.

From the preliminary survey, it was imperative that student trainees be integrated well in the restaurants as they were to work in the restaurants for 10 months and their performance would certainly influence the overall performance of the restaurant as a whole. The object of this study was to find out if cultural fits between organizations and student trainees could be found that might facilitate this integration process.

\section{Problem Formulation}

Three problem statements were formulated to be focused on, namely:

1. Which types of organizational culture are best for integrating PCU/Trisakti student trainees in SIR/FER restaurants in the Netherlands?

2. What success factors are there that can help SIR/FER restaurants better integrate the student trainees?

3. Do expectations and perceptions of the student trainees of Petra and those of Trisakti in terms of organizational cultures of SIR and FER restaurants differ so much?

\section{Hypothesis Development}

There were five hypothesis tested in the research, namely:

1. There is a difference in the types of organizational culture between SIR and FER restaurants.
2. There is a difference in expectations between Petra and Trisakti student trainees.

3. There is a difference in fits between SIR with Petra or Trisakti student trainee and FER with Petra or Trisakti student trainee.

4. There is a difference in expectations between the student trainees of 2001/2002 and 2002/2003.

5. There is a difference between the expectations and the perceptions of the types of organizational culture.

\section{CONCEPTUAL MODEL}

Figure 2 is the conceptual model developed to clarify the frameworks of thinking.

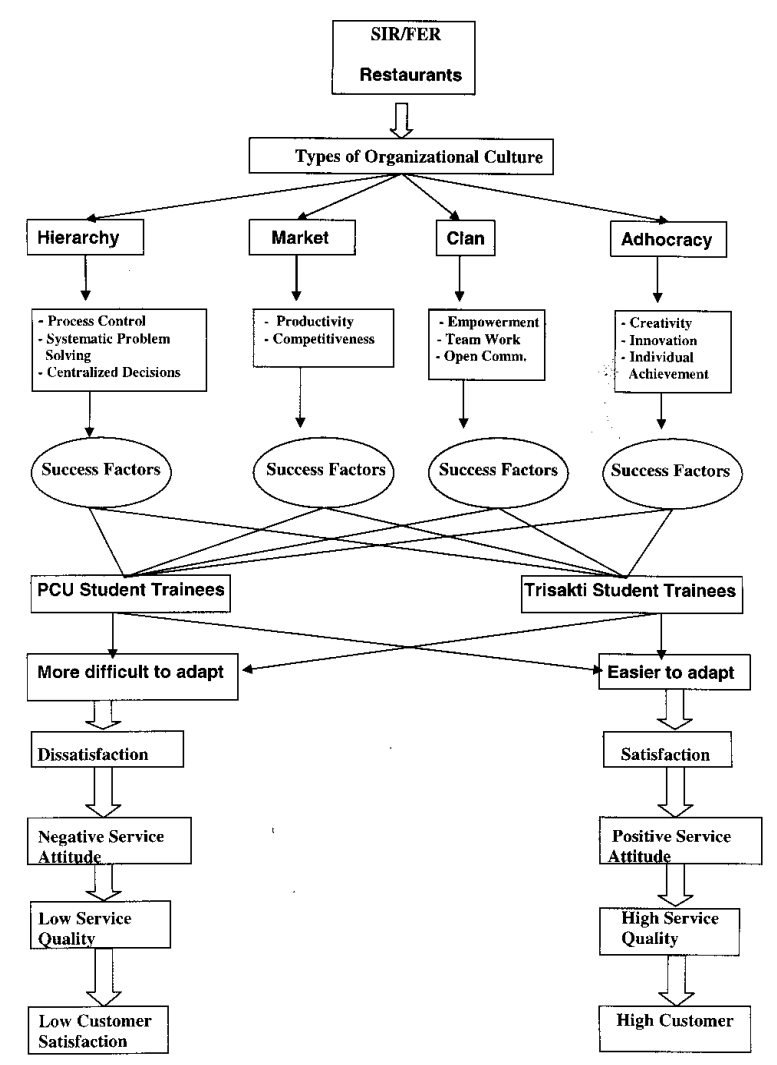

Figure 2. Conceptual Model: Satisfaction Procedure/Design

Two SIR restaurants were chosen as samples in which one restaurant took two student trainees from Petra and the other one took two Trisakti student trainees. In addition to the two SIR restaurants, two other restaurants belonging to FER were chosen in which one of them took two student trainees from Petra and the other one took two Trisakti students. Both quantitative and qualitative methods were used to collect data from respondents consisting of restaurant owners, permanent staff, company supervisors and student trainees. They responded to questionnaires and answered questions during in- 
depth interviews. Moreover, as a comparison to the data gathered, questionnaires were also distributed to the student trainees from a following cohort of students from both Petra and Trisakti to know about their preferred types of organizational culture in restaurants where they were going to be placed.

A well-developed questionnaire presented by Cameron and Quinn was used to collect data on the perception and expectation of the respondents upon the organizational culture of the restaurant where they worked. Parallel to that, the respondents were engaged in the in-depth interviews aimed at checking their consistency in revealing their opinions. This was important to ensure reliability of the data collected. Qualitative data is useful in "supplementing and illustrating" the quantitative data obtained from an experiment or survey (Robson, 1993).

The questionnaire consisted of six questions inquiring the respondents' opinion about the dominant characteristics of the organization, the leadership, the way employees is managed, the organization glue, the strategic emphases and the criteria of success in the organization. Each question had four choices of descriptions. The respondents were to give scores to each choice. They could divide 100 points to the four choices of descriptions. They gave the highest score to one of the four descriptions which they believed to give the closest description of the real situation of the organization. Then, respondents gave a score again for the same six questions to describe how they wished them to be (see table 1 ).

\section{Table 1. Example Questionnaire}

\section{Dominant Characteristics} Now

A. The organization is a very personal place. It is like an extended family. People seem to share a lot of themselves.

B. The organization is a very dynamic and entrepreneurial place. People are willing to stick their necks out and take risks.

C. The organization is very results oriented. A major concern is with getting the job done. People are very competitive and achievement oriented.

D. The organization is a very controlled and structured place. Formal procedures generally govern what people do.

\begin{tabular}{cc}
\hline Total & 100 \\
\hline
\end{tabular}

Source: Cameron \& Quinn, 1999

The in-depth interview was held with each respondent who had completed the questionnaire. However, one respondent was unable to join in the interview but his questionnaire was valid and was considered in the data analysis.

\section{Limitations}

Due to the limited time and research funds, the research was limited around the diagnosing of the organizational culture of two SIR restaurants and two FER restaurants in four different fits with the student trainees of PCU or Trisakti. The success factors which were very helpful for the restaurant management to better integrate the student trainees were observed as well. However, the research was not aimed at observing the influence of a certain type of organizational culture on customer satisfaction. In the actual data collection, however, two targeted respondents were unable to participate. Therefore instead of 20 to 24 respondents, only 19 respondents could participate in the project.

\section{RESULTS AND DATA ANALYSIS}

In the research, we managed to gather three types of data. The first types of data were data collected from the questionnaires completed by the respondents who were members of the four subjected restaurants. From these data, we acquired data showing the perceived and expected types of the organizational cultures of the restaurants where the respondents worked. Secondly, we obtained data from the in-depth interview with the respondents who had completed the questionnaires in which it allowed us to cross-validate the data from the questionnaires with the data from the interview regarding the perceived and expected types of the organizational cultures of the restaurants. Then, in the third types of data, we gained data from the questionnaires completed by the students who were about to do their job placement regarding their expectation of the type of organizational culture; in which in the analysis, the data were compared with the expectation of the students who were doing their traineeship.

In general, the results of the data collected from the questionnaire showed that most of the respondents in each of the restaurant perceived that the organizational culture was more Clan than the other three types of culture. While the preferred organizationnal culture was more a mixed of the four types of culture. The summary of the result from the questionnaire can be observed in the following tables and diagrams.

Restaurant 1 is an Oriental restaurant which belonged to FER. It dealt with Petra student trainees. 
Table 2. Organizational Culture Scoring in Restaurant 1

\begin{tabular}{|c|c|c|c|c|c|c|c|}
\hline No & Position/Role & Sex & Age & $\begin{array}{l}\text { Clan } \\
\text { (A) }\end{array}$ & $\begin{array}{c}\text { Adhocracy } \\
\text { (B) }\end{array}$ & $\begin{array}{c}\text { Market } \\
\text { (C) }\end{array}$ & $\begin{array}{l}\text { Hierarchy } \\
\text { (D) }\end{array}$ \\
\hline \multirow{2}{*}{1.} & \multirow{2}{*}{ Owner/ Manager } & \multirow{2}{*}{ Male } & \multirow{2}{*}{49} & $\mathrm{P}: \mathbf{4 0 . 8}$ & $\mathrm{P}: 14.5$ & $\mathrm{P}: 15.3$ & $\mathrm{P}: 29.3$ \\
\hline & & & & E:31.6 & $\mathrm{E}: 21.7$ & E: 19.2 & $E: 27.5$ \\
\hline \multirow{2}{*}{2.} & Uw & \multirow{2}{*}{ Female } & \multirow{2}{*}{44} & $P: 41.7$ & $\mathrm{P}: 15.8$ & $\mathrm{P}: 10.8$ & $\mathrm{P}: 31.7$ \\
\hline & Company & & & $\mathrm{E}: 33.3$ & $\mathrm{E}: 22.5$ & E: 15.8 & $E: 28.3$ \\
\hline \multirow[b]{2}{*}{3} & \multirow{2}{*}{ Employee (1) } & \multirow{2}{*}{ Female } & \multirow{2}{*}{42} & $\mathrm{P}: 36.6$ & $\mathrm{P}: 17.5$ & $\mathrm{P}: 18.3$ & $\mathrm{P}: 27.5$ \\
\hline & & & & $\mathrm{E}: 38.3$ & $\mathrm{E}: 15$ & $\mathrm{E}: 10$ & $E: 36.7$ \\
\hline \multirow{2}{*}{4.} & \multirow{2}{*}{ Employee (2) } & \multirow{2}{*}{ Female } & \multirow{2}{*}{21} & $\mathrm{P}: \mathbf{4 0 . 8}$ & $\mathrm{P}: 4.5$ & $\mathrm{P}: 10$ & $P: 44.2$ \\
\hline & & & & $\mathrm{E}: 26.7$ & $\mathrm{E}: 13.3$ & $\mathrm{E}: 16.6$ & $\mathrm{E}: 43.3$ \\
\hline \multirow{2}{*}{5.} & \multirow{2}{*}{ Student Trainee (1) } & \multirow{2}{*}{ Male } & & $\mathrm{P}: 25$ & $\mathrm{P}: 28.3$ & $\mathrm{P}: 22.5$ & $\mathrm{P}: 25$ \\
\hline & & & & $\mathrm{E}: 20.8$ & E : 25.8 & $\mathrm{E}: 22.5$ & $E: 30.8$ \\
\hline \multirow{4}{*}{6.} & \multirow{2}{*}{ Student Trainee (2) } & \multirow{2}{*}{ Female } & & $\mathrm{P}: \mathbf{3 0 . 8}$ & $\mathrm{P}: 15.8$ & $\mathrm{P}: \mathbf{2 5 . 8}$ & $P: \mathbf{2 7 . 5}$ \\
\hline & & & & $E: 35$ & $\mathrm{E}: 18.3$ & $\mathrm{E}: 15.8$ & $\mathrm{E}: 15.8$ \\
\hline & Mean & & & P:36.95 & $\mathrm{P}: 16.06$ & $\mathrm{P}: 17.1$ & $\mathrm{P}: \mathbf{3 0 . 8 6}$ \\
\hline & Scores & & & $E: 30.95$ & E: 19.43 & $\mathrm{E}: 16.65$ & $E: 30.4$ \\
\hline
\end{tabular}

P : Perception; E : Expectation

Source: primary data, analyzed

From table 2, it was observable that the organizational culture in restaurant 1 was more Clan dominant in combination with Hierarchy. Hence, the expectation was more a balanced combination between Clan and Hierarchy types. To show it more clearly, the scoring for both perception and expectation is shown in the diagrams in figure 3 and figure 4.

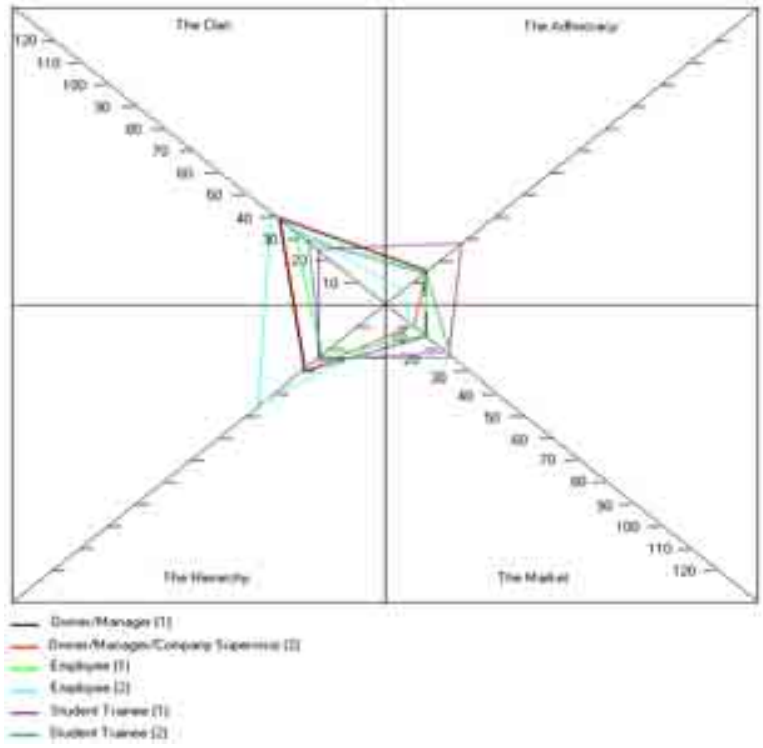

Figure 3. The Diagram of Perceived Organizational Culture of Restaurant 1

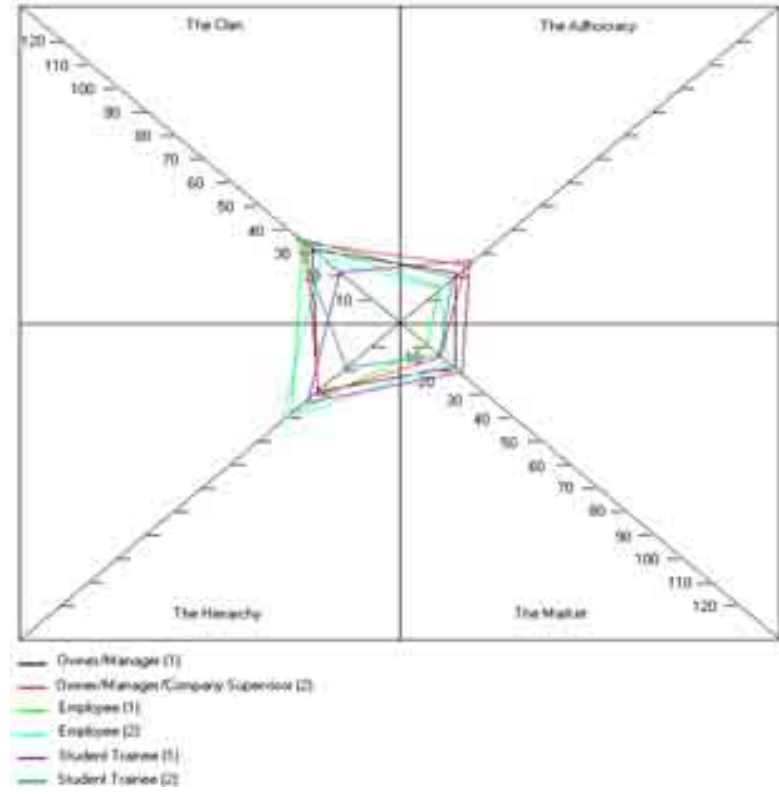

Figure 4. The Diagram of Expected Organiztionl Culture of Resturant 1

Restaurant 2 is an Indonesian restaurant which was a member of SIR. It dealt with Trisakti student trainees.

Table 3. Organizational Culture Scoring in Restaurant 2

\begin{tabular}{|c|c|c|c|c|c|c|}
\hline Position/Role & Sex & Age & $\begin{array}{l}\text { Clan } \\
(\mathrm{A})\end{array}$ & $\begin{array}{c}\text { Adhocracy } \\
\text { (B) }\end{array}$ & $\begin{array}{c}\text { Market } \\
\text { (C) }\end{array}$ & $\begin{array}{l}\text { Hierarchy } \\
\text { (D) }\end{array}$ \\
\hline \multirow{2}{*}{ 1. Owner } & Male & 53 & $\mathrm{P}: 40$ & $P: 25$ & $\mathrm{P}: 13.3$ & $P: 16.6$ \\
\hline & & & $E: 40$ & E: 25 & $\mathrm{E}: 13.3$ & $\mathrm{E}: 16.6$ \\
\hline \multirow{2}{*}{$\begin{array}{l}\text { 2. Manager \& Company } \\
\text { Supervisor }\end{array}$} & Male & 52 & $\mathrm{P}: \mathbf{2 6 . 7}$ & $\mathrm{P}: 23.3$ & $\mathrm{P}: 29.2$ & $\mathrm{P}: 20.8$ \\
\hline & & & E:26.7 & $\mathrm{E}: 23.3$ & E: 29.2 & $\mathrm{E}: 20.8$ \\
\hline \multirow{2}{*}{ 3. Employee } & Female & 24 & $\mathrm{P}: 47.5$ & $\mathrm{P}: 18$ & $\mathrm{P}: 8.7$ & $P: 25.8$ \\
\hline & & & $E: 47.8$ & $\mathrm{E}: 17.7$ & E: 16 & E:18.3 \\
\hline \multirow[t]{2}{*}{ 4. Student Trainee } & Male & 22 & $\mathrm{P}: \mathbf{8 0}$ & $\mathrm{P}: 5.8$ & $\mathrm{P}: 4.2$ & $\mathrm{P}: 10$ \\
\hline & & & $E: 100$ & $\mathrm{E}: 0$ & $E: 0$ & $\mathrm{E}: 0$ \\
\hline \multirow[t]{2}{*}{ 5. Student Trainee } & Male & 26 & $\mathrm{P}: 27.5$ & $\mathrm{P}: 17.5$ & $\mathrm{P}: 36.7$ & $\mathrm{P}: 18.3$ \\
\hline & & & E:27.5 & $\mathrm{E}: 17.5$ & $E: 36.7$ & $\mathrm{E}: 18.3$ \\
\hline & & & P: 44.34 & P: 17.92 & P: 18.42 & P: 18.30 \\
\hline Sco & & & E: 49.20 & E: 16.70 & E: 19.04 & E: 10.80 \\
\hline
\end{tabular}

P : Perception; E : Expectation

Source: primary data, analyzed

From table 3, we found out that restaurant 2 like restaurant 1 had a very dominant Clan type of organizational culture as the mean score was the highest among the other three types of cultures both for the perception and for the expectation. The scoring can be described in the diagrams in figure 5 and figure 6. 




Figure 5. The Diagram of Perceived Organizational Culture of Restaurant 2

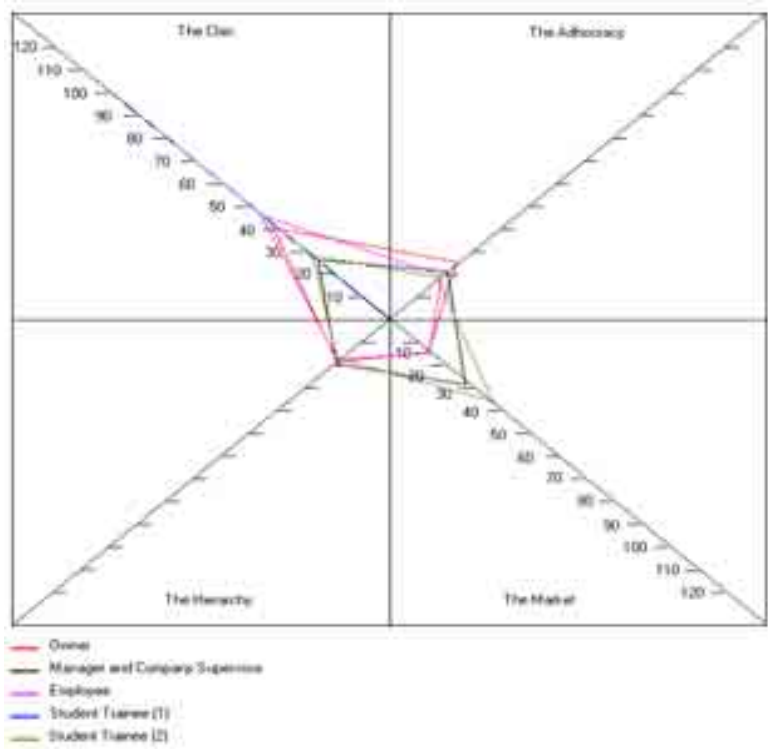

Figure 4. The Diagram of Expected Organiztionl Culture of Resturant 2

After comparing all the perceived and expected diagrams of organizational culture types of the four subjected restaurants, we found out that the difference between them was generally not significant. However, the mean score for Clan type in the expected diagram was higher than the perceived one signifying that they were happy with the present organizational culture but they expected that it would be more Clan.

In the next stage of the data analysis, we also compared the result of the questionnaires with the result of the in-depth interview in which we found out that all of the respondents were consistent with their answers both in filling the questionnaire and in answering the questions in the interview. That was very important to prove the validity of the data gathered. There were several expressions used by the respondents in the interview that reflected Clan type of organizational culture. For example in restaurant 1 which is an Oriental restaurant dealing with the Petra students, the respondents described the relationship between the owners or the restaurant and the employees as well as the student trainees as "a big family" in which the owners treated the employees and the student trainees as their "sons" and "daughters". The owners felt responsible for keeping the business alive for the people who worked for them. The owners and the employees including the student trainees sometimes had social activities together after work. When they worked, they were expected to work in teams and helped each other. The owners became mentors for the others and they worked together with the teams. They also involved the employees and the student trainees in running the business by involving them in the meetings which were done regularly to evaluate things, to solve problems and to make changes. Those descriptions reflected very much the characteristics of Clan type of organizational culture in which the respondents also revealed in the results of the questionnaires.

As for restaurants 2, 3 and 4, we found out that the respondents also revealed that the relationship was more like a family and that they were expected to cooperate in teams. The owners put a large amount of concern on personal development. Besides that, we also found out that most of the respondents were happy with the present organizational cultures and they would prefer that the restaurants would maintain the present organizational cultures which were dominant Clan. We also focused on analyzing the student trainees' expectations and found out that they were happy and felt comfortable with the Clan type of organizational culture and most of them wanted the organizational culture to be more Clan than the other type of organizational cultures.

In addition to this, we distributed the questionnaires to the student trainees of 2002/2003 to observe their expectation of what kind of organizational culture they expected from the restaurant they were going to be placed and the result was indeed supporting the previous result in which the highest mean score for both PCU students' and Trisakti students' expectation was for Clan type of organizational culture as seen in the summary of the mean score results in table 3 . 
Table 4. Summary of Mean Score Results of Expected Organizational Culture

\begin{tabular}{lcccc}
\hline \multirow{1}{*}{ Respondents } & \multicolumn{4}{c}{ Mean Scores } \\
\cline { 2 - 5 } & The Clan & $\begin{array}{c}\text { The } \\
\text { Adhocracy }\end{array}$ & $\begin{array}{c}\text { The } \\
\text { Market }\end{array}$ & $\begin{array}{c}\text { The } \\
\text { Hierarchy }\end{array}$ \\
\hline $\begin{array}{l}\text { PCU students of } \\
\text { 2001/2002 }\end{array}$ & $\mathbf{4 0 . 4 0}$ & 18.13 & 14.73 & 22.28 \\
\hline $\begin{array}{l}\text { PCU students of } \\
\text { 2002/2003 }\end{array}$ & $\mathbf{4 2 . 4 1}$ & 20.78 & 14.23 & 21.95 \\
$\begin{array}{l}\text { Trisakti students of } \\
\text { 2001/2002 }\end{array}$ & $\mathbf{4 3 . 7 5}$ & 18.50 & 19.78 & 18.15 \\
$\begin{array}{l}\text { Trisakti students of } \\
\text { 2002/2003 }\end{array}$ & $\mathbf{3 9 . 4 5}$ & 20.83 & 17.17 & 24.25 \\
\hline
\end{tabular}

Source: primary data, analyzed

Moreover, we also found out from the qualitative data gathered from the in-depth interview some success factors in hiring and dealing with Indonesian student trainees, in this case, PCU and Trisakti student trainees. In the first place, it was essential to treat the students like part of the big family and members of the teamwork as that was the key to successful approach to deal with them. By treating the students like part of the family, they felt more at ease so that later on they wanted to open up themselves and adapted with the new situation. Secondly, it was also important to give enough time for orientation and discuss both parties expectations from the very beginning in which it was helpful for both parties to minimize factors which later on would cause dissatisfactions. Then the next success factor was involving the student trainees in decision making as they would feel important. This approach is "suggestion involvement" which is one part of empowerment. (Bowen and Lawler III, 1995; Lashley, 2001; Tschohl, 2002). Another success factor was to give them right to speak out their ideas. That was important to add to the student's enthusiasm in performing the job. Still, it was also imperative to give them trust and responsibilities as we would be practicing "job involvement" as the students were given freedom in deciding how to do the work; and handle a whole, identifiable piece of work. This approach leads to the student trainees' higher satisfaction and motivation in doing the work and they do higher quality work (Bowen and Lawler III, 1995; Lashley, 2001; Tschohl, 2002). Furthermore, finding the agreed common language would minimize problems due to language barrier as the student trainees were more familiar with English than Dutch whereas management and regular employees were in contrast more familiar with Dutch than English. However, when problems appeared due to language barrier or culture differences, maintaining an open communication was the best way to solve the problems. Last but not least, it was tremendously important to treat the student trainees the same as the other employees as they would not be that cooperative anymore if they felt they were discriminated.

\section{CONCLUSION AND FURTHER RESEARCH}

For a service agent to deliver quality service, he needs to be satisfied with his job and work environment in general. If employee satisfaction does not exist, it is almost impossible to reach customer satisfaction since they are interrelated to each other. Organizational culture is one of the factors which may influence employee satisfaction. If an employee disagrees with the culture of the organization he works for, he is more likely to feel dissatisfied with his job.

As SIR and FER restaurants employ Indonesian student trainees in their daily operations, it is imperative for them to make the trainees feel comfortable with the organizational culture of the restaurants where they are placed; otherwise they will not be satisfied and perform well which in the end will lead to customer dissatisfaction. In the research it has been observed and analyzed that all of the Indonesian student trainees, either from PCU or Trisakti, expect to work in organizations whose organizational culture is predominantly Clan. In addition, there was no difference in expectations between the student trainees of 2001/2002 and 2002/2003. From the two samples of SIR restaurants and two other samples of FER restaurants, it was found out that their organizational cultures were basically Clan culture. Therefore, the student trainees were happy working in the restaurants. We can conclude that Indonesian student trainees are basically suitable to be placed in organizations whose dominant organizational culture is Clan culture.

Regarding the fits, we found out that there was no difference in fits between SIR with Petra and Trisakti student trainee and FER with Petra and Trisakti student trainee. In this case, it was difficult to analyze the fits as three of the restaurants dealt only with one kind of student trainees from one specific school, for example from PCU or from Trisakti. Only one restaurant, had ever dealt with both types of students and the restaurant found out there was no big difference between the two students in terms of motivation and adaptation.

There was a difference between the expectations and perceptions of the types of the organizational culture of each restaurant eventhough the difference was not significant. It signifies that most of the respondents were happy with the present organizational culture of the restaurants where they work.

Hence, it is recommended that for there will be a further research that will analyze the influence of the organizational culture on the performance of the student trainees and the customer satisfaction. 
Specifically, the research is aimed at analyzing the influence of Clan type of organizational culture on the performance of the Indonesian student trainees whether it will result to higher customer satisfaction due to their improved service quality.

\section{REFERENCES}

Bowen, D.E. and Edward E. Lawler III. (1995), "Organising for service: Empowerment or production line?"in Glynn, William J. and James G. Barnes, ed. Understanding services management: Integrating marketing, organisational behaviour, operations and human resource management. Chichester: Wiley.

Cameron, Kim S. and Robert E. Quinn. (1999), Diagnosing and changing organizational culture: Based on the competing values framework. Massachusetts: Addison-Wesley.

Frost, P. J. et.al. (1985), Organizational culture. California: Sage Publications.

Harris, P. R. and Robert T. M. Managing cultural differences: Leadership strategies for a new world of business. Houston: Gulf Publishing Company, 1996.
Heskett, J. L., Sasser, Jr. E.W., and Leonard A. S. (1997), The service profit chain: How leading companies link profit and growth to loyalty, satisfaction, and value. New York: The Free Press.

Lashley, C. (2001), Empowerment: HR strategies for service excellence. Oxford: Butterworth-Heinemann.

Robson, C. (1993), Real world research, Oxford: Blackwell Publishers.

Sparrow, P.R. and Hiltrop, J.M. (1994), European human resource management in transition. New York: Prentice Hall.

Schein, E. H. (1992), Organizational culture and leadership. (2 $2^{\text {nd }}$. ed.) San Francisco: Jossey-Bass Publishers.

Schneider, B. (1990), Organizational climate and culture. San Fransisco: Jossey-Bass Publishers.

Tschohl, J. (2002), The power of empowerment. [downloaded from www.customer-service. com.]

Zeithaml, V. A. and Mary J. B. (2000), Services marketing: Integrating customer focus across the firm. ( $3^{\text {rd }}$ ed.), Boston: McGraw-Hill. 